\title{
Differences in Gastroprotective and Mutagenic Actions Between Polar and Apolar Extracts of Ananas ananassoides
}

\author{
J.S. Silva, ${ }^{1}$ M.A. Andreo, ${ }^{2}$ F.R. Tubaldini,${ }^{3}$ E.A. Varanda,${ }^{3}$ L.R.M. Rocha, ${ }^{1}$ A.R.M.S. Brito, ${ }^{4}$ \\ W. Vilegas, ${ }^{2}$ and C.A. Hiruma-Lima ${ }^{1}$ \\ ${ }^{1}$ Physiology Department, Biosciences Institute, São Paulo State University, Botucatu; ${ }^{2}$ Organic Chemistry \\ Department, Chemistry Institute, and ${ }^{3}$ Biological Science Department, Pharmaceutical Sciences Faculty, \\ São Paulo State University, Araraquara; and ${ }^{4}$ Physiology and Biophysics Department, \\ Biology Institute, Campinas State University, Campinas, São Paulo, Brazil
}

\begin{abstract}
Several plants are used in folk medicine to treat gastrointestinal disorders. Ananas ananassoides (Baker) L.B. Smith (Family Bromeliaceae) is a medicinal plant commonly used in the central region of Brazil against gastric pain. We evaluated two extracts (methanol $[\mathrm{MeOH}]$ and dichloromethane [DCM]) obtained from the leaves of A. ananassoides for their ability to protect the gastric mucosa against injuries caused by necrotizing agents $(0.3 \mathrm{M} \mathrm{HCl} / 60 \%$ ethanol, absolute ethanol, non-steroidal anti-inflammatory drugs, and pylorus ligation) in mice and rats. The best results were obtained after pretreatment with the DCM extract, whereas the $\mathrm{MeOH}$ extract did not show any significant anti-ulcerogenic activity but presented mutagenic action. The mechanism of action of the DCM extract suggested the effective participation of endogenous sulfhydryl group in the gastroprotective action. The data, taken together with the absence of acute toxicity and mutagenicity, indicate the apolar extract, instead of the polar, extract of $A$. ananassoides as a safe and potential new anti-ulcerogenic drug.
\end{abstract}

KEY WORDS: • Ananas ananassoides • anti-ulcerogenic activity • Bromeliaceae • endogenous sulfhydryls • mutagenicity

\section{INTRODUCTION}

$\mathbf{U}^{\prime}$ LCERS RELATED TO Helicobacter pylori infection are becoming scarce. However, peptic ulcers associated with the use of non-steroidal anti-inflammatory drugs (NSAIDs) remain a major clinical problem, which has not been solved by introduction of selective inhibitors of cyclooxygenase. ${ }^{1}$ In addition, the literature reveals the large variety of chemical compounds isolated from medicinal plants with anti-ulcer activity. ${ }^{2}$ Ananas ananassoides is a widespread plant in Cerrado lands popularly known as "abacaxi-do-cerrado," "ananás-de-raposa," and "macambira." Its fruits are used to make juice, wine, and ice cream. ${ }^{3}$ In traditional folk medicine, decocted aerial parts of $A$. ananassoides are used as a treatment for ulcers and gastrointestinal disturbances. ${ }^{4}$ Despite the popular use of this species as a medicinal plant, there are no data on its pharmacological and mutagenic effects, phytochemical constituents, or possible toxic property.

Therefore, the present study has been conducted to eval-

\footnotetext{
Manuscript received 2 July 2007. Revision accepted 21 October 2007.
}

Address reprint requests to: C.A. Hiruma-Lima, Physiology Department, Biosciences Institute, São Paulo State University, C.P. 510, 18618-000, Botucatu, SP, Brazil, E-mail: hiruma@ibb.unesp.br uate the mutagenic activity in Salmonella/microsome assays, using different in vivo experimental models in rodents to evaluate the acute toxicity and anti-ulcer activity of two organic extracts (dichloromethane [DCM] and methanol $[\mathrm{MeOH}])$ obtained from $A$. ananassoides leaves.

\section{MATERIALS AND METHODS}

\section{Extraction, fractionation, and identification}

Leaves of A. ananassoides were collected at Porto Nacional city, in the state of Tocantins, Brazil, by C.A.H.-L. A flowered voucher was identified by Prof. Solange Lolis from the Universidade Federal do Tocantins, Porto Nacional city, and deposited under voucher number 7161 at the Herbário do Tocantins herbarium. Dry leaves $(600 \mathrm{~g})$ of $A$. ananassoides were powdered and macerated with $1 \mathrm{~L}$ of $\mathrm{DCM}$ or $\mathrm{MeOH}$ successively at room temperature (1 week for each solvent). The solutions were filtered through filter paper, and the solvent was evaporated under reduced pressure affording $12 \mathrm{~g}$ ( $2 \%$ of the dry weight) of DCM extract and $30 \mathrm{~g}(5 \%)$ of $\mathrm{MeOH}$ extract.

An aliquot of DCM extract (3.0 g) was fractionated by silica gel column chromatography eluted with gradient mixtures of hexane/ethyl acetate to produce 100 fractions. These fractions were checked by thin-layer chromatography on sil- 
ica gel plates using mixtures of hexane/ethyl acetate as eluent and revealed with iodine vapors and/or anisaldehyde/sulfuric acid, which showed that the fractions were divided into 19 groups. Fractions 1 and 8 were purified by successive column chromatography over silica gel, allowing the identification of hydrocarbons and fatty acid ester. Fraction 9 (90 mg) was purified using silica gel column chromatography, leading to the identification of the compounds stigmasterol 1, sitosterol 2, and campesterol $\mathbf{3}$ (Fig. 1) by gas chromatography-flame ionization detector (model CP 3380, Varian, Walnut Creek, CA) using standard compounds available from our collection. Purification of fraction 12 (74.0 mg) was achieved by silica gel column chromatography using $\mathrm{CHCl}_{3} / \mathrm{MeOH} / \mathrm{H}_{2} \mathrm{O}$ (80:18:2, by volume) to yield pure the compounds $p$-coumaric acid $\mathbf{4}$ and caffeic acid $\mathbf{5}$ (Fig. 1), identified by nuclear magnetic resonance spectroscopy $(500 \mathrm{MHz}$ INOVA spectrometer [Varian, Palo Alto, CA], using dimethyl sulfoxide- $d_{6}$ as the solvent and trimethylsilane as the internal standard).

A portion $(10.0 \mathrm{~g})$ of the $\mathrm{MeOH}$ extract of $A$. ananassoides was partitioned with a mixture of ethyl acetate $/ \mathrm{H}_{2} \mathrm{O}$ $(1: 1, \mathrm{vol} / \mathrm{vol})$. The ethyl acetate fraction $(2.8 \mathrm{~g})$ was subjected to gel permeation chromatography on a Sephadex LH20 (Pharmacia, Uppsala, Sweden) column $(70 \times 3 \mathrm{~cm})$, eluted with $\mathrm{MeOH}$. We collected 120 fractions $(10 \mathrm{~mL})$, which were checked by thin-layer chromatography on silica gel plates eluted with a mixture of $\mathrm{CHCl}_{3} / \mathrm{MeOH} / \mathrm{H}_{2} \mathrm{O}$ (80:18:2, by volume) and revealed with anisaldehyde/sulfuric acid solution. Fractions showing similar thin-layer chromatography data were combined, affording 13 major fractions. Fraction $6(95.0 \mathrm{mg})$ was fractionated by successive column chromatography on silica gel (Merck, Whitehouse Station, NJ) eluted with $\mathrm{CHCl}_{3} / \mathrm{MeOH} / \mathrm{H}_{2} \mathrm{O}(80: 18: 2$, by volume), furnishing compounds $\mathbf{4}$ and $\mathbf{5}$ (Fig. 1) identified by nuclear magnetic resonance spectroscopy $(500 \mathrm{MHz} \mathrm{IN}-$

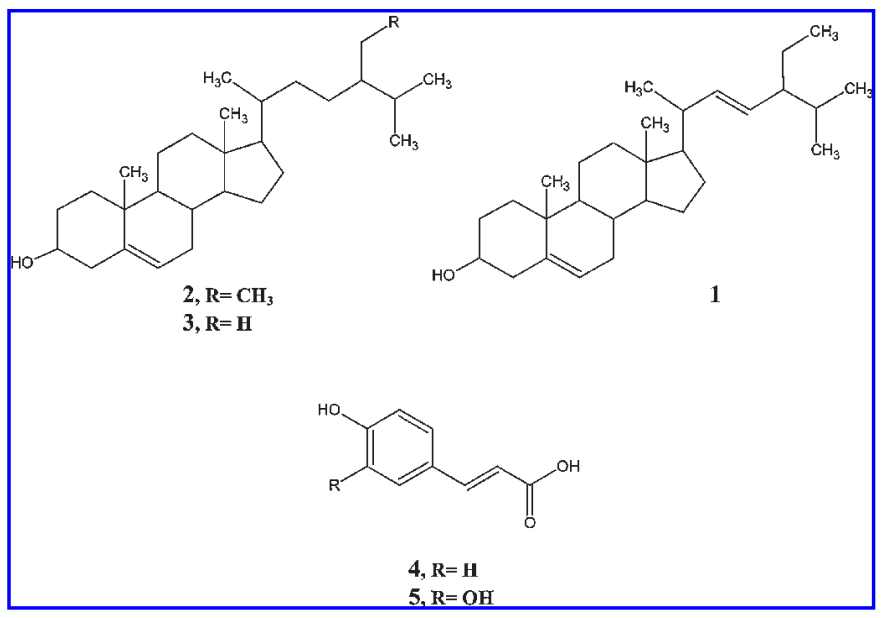

FIG. 1. Isolated and/or identified compounds in extracts of $A$. ananassoides: 1, stigmasterol; 2, sitosterol; 3, campesterol; 4, pcoumaric acid; and 5, caffeic acid.
OVA spectrometer, using dimethyl sulfoxide- $d_{6}$ as the solvent and trimethylsilane as the internal standard).

The $\mathrm{H}_{2} \mathrm{O}$ fraction $(7.0 \mathrm{~g}$ ) was analyzed by nuclear magnetic resonance spectroscopy, which determined that its main components are sugars (mainly glucose and fructose).

\section{Drugs and chemicals}

Hydrochloric acid, sodium hydroxide, ethanol (EtOH) (Vetec, S.A., São Paulo, Brazil), Tween 80 (Synth, São Paulo), cimetidine, $N^{\mathrm{G}}$-nitro-L-arginine methyl ester (LNAME), $N$-ethylmaleimide (NEM), carbenoxolone, atropine (Sigma Chemical Co., St. Louis, MO), piroxicam (Medley, São Paulo), and charcoal (Chemco, São Paulo) were used in this study. The $\mathrm{MeOH}$ extract was dissolved in saline (vehicle), and the DCM extract was dissolved in Tween 80 at $8 \%$. All substances were prepared immediately before use, and the reagents used were of analytical grade. All reagents used to prepare buffers and media were from Merck or Sigma Chemical Co. The S9 fraction from Aroclor 1254-treated rats was obtained from Molecular Toxicology, Inc. (Annapolis, MD).

\section{Animals}

All experiments were performed on male Swiss mice (weighing $30 \pm 5 \mathrm{~g}$ ) or male Wistar rats (weighing $280 \pm$ 20 g) obtained from the São Paulo State University Animal House in Botucatu, SP, Brazil. The animals were fed a certified Labina ${ }^{\circledR}$ (São Paulo) diet with free access to tap water and were housed in a 12-hour light/dark cycle at a temperature of $24 \pm 1{ }^{\circ} \mathrm{C}$. Fasting was used prior to all assays because both the standard drugs and extracts were always administered orally (by gavage) or intraduodenally using a saline solution $(10 \mathrm{~mL} / \mathrm{kg})$ or Tween 80 at $8 \%$ as the vehicle. The São Paulo State University Institutional Animal Care and Use Committee, following the recommendations of the Canadian Council on Animal Care, ${ }^{5}$ approved all of the protocols used.

\section{$\mathrm{HCl} / \mathrm{EtOH}$-induced ulcer}

The anti-ulcerogenic activity of the $\mathrm{MeOH}$ and DCM extracts obtained from A. ananassoides in this model was assessed in mice. ${ }^{6}$ Mice were divided into 10 groups $(n=$ $7-8)$, which were fasted for 24 hours prior to oral dosing with the vehicle (saline or Tween 80 at $8 \%$ ), lansoprazole $(30 \mathrm{mg} / \mathrm{kg}$ ), or $\mathrm{MeOH}$ or DCM extracts $(250,500$, or 1,000 $\mathrm{mg} / \mathrm{kg}$ ). Fifty minutes after the treatments, all animals received orally $0.2 \mathrm{~mL}$ of a $0.3 \mathrm{M} \mathrm{HCl} / 60 \% \mathrm{EtOH}$ solution. Animals were killed by cervical dislocation 1 hour after the administration of $\mathrm{HCl} / \mathrm{EtOH}$ solution; the stomachs were removed, opened along the greater curvature, and fixed between two glass plates. The ulcerative lesion index (ULI) was calculated according to the methodology described by Szelenyi and Thiemer. ${ }^{7}$ 


\section{NSAID-induced gastric ulcers in mice}

In this model, ${ }^{8}$ gastric ulcer was induced using piroxicam (30 mg/kg, s.c.) administered to mice $(n=4-8)$. The $\mathrm{MeOH}$ or DCM extracts from A. ananassoides $(250,500$, or 1,000 $\mathrm{mg} / \mathrm{kg}$ ), cimetidine $(100 \mathrm{mg} / \mathrm{kg}$ ), or vehicle (saline or Tween 80 at $8 \%$ ) were administered orally 30 minutes before the induction of gastric ulcer. The animals were killed by cervical dislocation 4 hours after treatment with the ulcerogenic agent. The stomachs were removed, and the ulcerative index was calculated as described previously.

\section{EtOH-induced ulcer}

After 24 hours of fasting, rats $(n=5-6)$ received an oral administration of $\mathrm{DCM}$ or $\mathrm{MeOH}$ extracts from A. ananassoides $(250,500$, or $1,000 \mathrm{mg} / \mathrm{kg})$, lansoprazole $(30 \mathrm{mg} / \mathrm{kg})$, or vehicle. One hour after treatment, all rats received $1 \mathrm{~mL}$ of $99.5 \% \mathrm{EtOH}$ to induce gastric ulcer. The animals were killed 1 hour after treatment with the ulcerogenic agent, and the stomachs were removed and opened along the greater curvature to determine the lesion damage. ${ }^{9}$

\section{Determination of activity on intestinal motility}

The effect of the extract on intestinal motility in mice was tested using the charcoal method. ${ }^{10}$ The animals were fasted for 12 hours but were allowed free access to water. They were randomized and placed in five cages with five animals per cage. Groups were pretreated orally with $\mathrm{DCM}$ or $\mathrm{MeOH}$ extract $(250,500$, or $1,000 \mathrm{mg} / \mathrm{kg})$, atropine $(5 \mathrm{mg} / \mathrm{kg})$, or vehicle. After 30 minutes, each mouse was administered activated charcoal $10 \%$ (10 mL/kg, p.o.). All animals were killed 30 minutes later by cervical dislocation, and the small intestine was rapidly dissected for measurement of the distance traversed by the charcoal meal from the pylorus to the ileocecal junction, expressed as a percentage of the total distance with the values transformed to arcsine for statistical analyses.

\section{EtOH-induced gastric mucosal lesion in L-NAME-pretreated rats}

The rats were fasted for 24 hours and were placed randomly into six cages with five animals per cage. The animals were treated with L-NAME (an inhibitor of nitric oxide synthase) $(70 \mathrm{mg} / \mathrm{kg})$ or saline intraperitoneally and 30 minutes later received an oral dose of the vehicle, carbenoxolone $(100 \mathrm{mg} / \mathrm{kg})$, or DCM extract $(500 \mathrm{mg} / \mathrm{kg})$. After 60 minutes, all groups were orally treated with $1 \mathrm{~mL}$ of absolute EtOH for gastric ulcer induction. ${ }^{11}$ Animals were killed 1 hour after the administration of EtOH by cervical dislocation, and the stomachs were excised; gastric damage was determined as described previously.

\section{Determination of gastric secretion}

All groups of mice ( $n=10-11)$ were fasted for 24 hours, with free access to water. Immediately after pylorus liga- ture, DCM extract from A. ananassoides $(500 \mathrm{mg} / \mathrm{kg})$, cimetidine $(100 \mathrm{mg} / \mathrm{kg})$ as a positive control, or vehicle was administered intraduodenally. The animals were killed 4 hours later by cervical dislocation; the abdomen was opened, and another ligature was placed around the esophagus close to the diaphragm. The stomachs were removed, and the gastric content was collected to determine the total amount of gastric juice acid (in $\mathrm{mL}$ ) and $\mathrm{pH}$ values. Distilled water was added, and the resultant solution was centrifuged at 3,000 $\mathrm{g}$ for 10 minutes. Total acid in the gastric secretion was determined in the supernatant volume by titration to $\mathrm{pH} 7.0$ with $0.01 \mathrm{~N} \mathrm{NaOH} .{ }^{12}$

\section{EtOH-induced gastric lesions in NEM-pretreated rats}

Rats were divided into groups of five animals that were fasted for 24 hours. They had been previously treated intraperitoneally with NEM $(10 \mathrm{mg} / \mathrm{kg})$ or saline. Thirty minutes later, the different groups received an oral dose of the vehicle, carbenoxolone $(100 \mathrm{mg} / \mathrm{kg})$, or DCM extract $(500$ $\mathrm{mg} / \mathrm{kg}$ ). After 60 minutes, all groups were orally treated with $1 \mathrm{~mL}$ of absolute EtOH for gastric ulcer induction. ${ }^{13}$ Animals were killed 1 hour after the administration of EtOH by cervical dislocation, the stomachs were excised, and gastric damage was determined as described previously.

\section{Acute toxicity studies}

Control and treated groups consisted of 10 animals each (Swiss male mice). The treated group received DCM extract, whereas the controls received saline by gavage at a single dose of $5,000 \mathrm{mg} / \mathrm{kg}$ of animal weight. The animals were observed carefully $30,60,120,240$, and 360 minutes after the treatment. The mortality, measured body weight, and behavioral screening were recorded once every 24 hours for 14 days following treatment. The macroscopic analyses and weight of vital organs such as the liver, kidney, heart, and lung were compared to those of animals treated with DCM extract and those receiving the vehicle. ${ }^{14}$

\section{Salmonella mutagenicity assay}

Mutagenicity was tested by the Salmonella/microsome assay, based on the preincubation method, ${ }^{15}$ using the Salmonella typhimurium test strains TA97a, TA98, TA100, and TA102, kindly provided by Dr. B.N. Ames (University of California, Berkeley, CA), with and without metabolization. The test strains from frozen cultures were grown overnight for 12-14 hours in Oxoid (London, UK) Nutrient Broth No. 2. Various concentrations of $\mathrm{MeOH}$ extract $(2.75,5.25,10.5$, 15.75 , and $21.0 \mathrm{mg}$ per plate for strains TA100, TA98, TA97a, and TA102) and DCM extract $(1.75,3.5,7.0,10.5$, and $14.0 \mathrm{mg}$ per plate for TA98 and TA100 and 0.04, 0.09, $0.17,0.26$, and $0.35 \mathrm{mg}$ per plate for TA102 and TA97a) dissolved in dimethyl sulfoxide were added to $100 \mathrm{~L}$ of bacterial culture and $0.5 \mathrm{~mL}$ phosphate buffer $(\mathrm{pH} 7.4)$ or 0.5 $\mathrm{mL}$ of $\mathrm{S} 9$ mixture and incubated for $20-30$ minutes at $37^{\circ} \mathrm{C}$. 
After the incubation, $2 \mathrm{~mL}$ of top agar was added, mixed, and then poured onto a plate of minimal agar. The plates were incubated at $37^{\circ} \mathrm{C}$ for 48 hours, and $\mathrm{His}^{+}$revertant colonies were enumerated with an automatic counter (ProtoCOL, Synbiosis, Cambridge, UK). All experiments were analyzed in triplicate. The concentrations were selected on the basis of a preliminary toxicity test. In all subsequent assays, the upper limit of the dose range tested was either the highest nontoxic dose or the lowest toxic dose determined in this preliminary assay. Toxicity was apparent either as a reduction in the number of $\mathrm{His}^{+}$revertants or as an alteration in the autotrophic background (i.e., background lawn). The statistical analysis was performed with the Salanal computer program. ${ }^{16}$ The mutagenic index was also calculated for each dose, as the average number of revertants per plate divided by the average number of revertants per plate in the negative (solvent) control. A sample was considered positive when the mutagenic index was $\geq 2$ for at least one of the tested doses and if it had a reproducible dose-response curve. $^{17}$

The standard mutagens used as positive controls in each experiment were 2 -aminoanthracene $(1.25 \mu \mathrm{g}$ per plate) and sodium azide $(1.25 \mu \mathrm{g}$ per plate) for TA100, 4 nitro- $O$ phenylenediamine (10 $\mu \mathrm{g}$ per plate) and 2-aminoanthracene (1.25 $\mu \mathrm{g}$ per plate) for TA98 and TA97a, and mitomycin C $(0.25 \mu \mathrm{g}$ per plate) and 2 -aminofluorene ( $5 \mu \mathrm{g}$ per plate) for TA102. Dimethyl sulfoxide served as the negative (solvent) control.

\section{Statistical analyses}

The results are presented as mean \pm SE values. One-way analysis of variance (ANOVA) followed by Dunnett's or Fisher's pairwise test was employed for comparing three or more groups. Values of $P<.05$ were considered significant.

\section{RESULTS AND DISCUSSION}

Natural products research is guided in many cases by ethnopharmacological knowledge and has made substantial contributions to drug innovation by providing novel chemical structures and/or action mechanisms. ${ }^{18}$ In Brazil, a large number of herbal extracts are used in folk medicine to treat various types of digestive disorders. ${ }^{19,20}$

A. ananassoides is a medicinal plant commonly used in folk medicine to treat stomachache, but there are no data about its pharmacological action on the gastrointestinal system or its possible toxic and mutagenic effects. Since the ethnopharmacological information about the dosing employed for A. ananassoides was imprecise and because active principles contained in crude extracts are normally found in small amounts, in this work we used a maximum dose of crude extract of $1,000 \mathrm{mg} / \mathrm{kg}$ in order to compare its activity with those obtained using the typical doses for commercial drugs such as cimetidine (100 $\mathrm{mg} / \mathrm{kg}$ ), carbenoxolone $(100 \mathrm{mg} / \mathrm{kg})$, or lansoprazole (30 $\mathrm{mg} / \mathrm{kg}$ ).
We evaluated the effect of $\mathrm{MeOH}$ and DCM extracts obtained from A. ananassoides administered to rodents using the different standard experimental models of induced gastric ulcer. In order to establish a general profile of the antiulcerogenic activity of extracts that would permit us to characterize its mechanism of action, we plotted the dose-response curve using three oral doses of 250,500 , and $1,000 \mathrm{mg} / \mathrm{kg}$, p.o., to select the dose that produces the best effect.

The ability of gastric mucosa to resist injury produced by endogenous secretions (acid, pepsin, and bile) and by ingested irritants (e.g., alcohol) can be attributed to a number of factors that have been collectively referred to as mucosal defense. ${ }^{1}$ The formation of gastric mucosal lesions by necrotizing agents such as $\mathrm{HCl}$ and $\mathrm{EtOH}$ has been reported to involve the depression of these gastric defensive mechanisms. $\mathrm{HCl} / \mathrm{EtOH}$-induced gastric ulcers also promote stasis in gastric blood flow that contributes to development of the hemorrhagic and necrotic aspects of tissue injury. ${ }^{21}$

In the $\mathrm{HCl} / \mathrm{EtOH}$-induced gastric ulcers, the lesions were characterized by multiple hemorrhage red bands of different sizes along the long axis of the glandular stomach. Compared to the control value, administration of lansoprazole and of the DCM extract significantly inhibited ulcerative lesion at all doses, but treatment with the $\mathrm{MeOH}$ extract showed significant activity only at the highest dose (Table 1). EtOH-induced ulcers are not inhibited by antisecretory agents such as cimetidine but are inhibited by agents that enhance mucosal defensive factors such as prostaglandins. ${ }^{9}$ Therefore, our results suggest that the DCM extract has an anti-ulcerogenic effect related to cytoprotection. Many isoprenoids, including carbenoxolone and sterols, are known to present anti-ulcer activity, and the hydroxyl group at the C3 position seems to be a prerequisite for their anti-ulcer activity. ${ }^{22}$ In fact, $\beta$-sitosterol (present in the DCM extract composition) is one of the active steroids of Amphipterygium adstringens (Family Julianaceae) and displayed a moderate gastroprotective activity. ${ }^{11}$

NSAIDs such as aspirin, piroxicam, and indomethacin remain among the most commonly used pharmacological agents. ${ }^{23}$ However, these classes of substances may cause gastrointestinal ulceration because of the ability of these agents to suppress prostaglandin synthesis. ${ }^{1}$ Table 1 indicates a discrete anti-ulcerogenic effect of the $\mathrm{MeOH}$ and DCM extracts in the NSAID-induced lesion models, since significant reductions in gastric mucosal damage were achieved only after pretreatment with the highest dose.

Alcohol is an etiological factor closely related to gastric mucosal damage. Intragastric absolute EtOH administration to 24hour-fasted rats produced linear hemorrhagic lesions, extensive submucosal edema, mucosal friability, inflammatory cells, and epithelial cell loss in the stomach, which are typical characteristics of alcohol injury. ${ }^{24}$ The pathogenesis of EtOHinduced gastric mucosal damage is still unknown, but the damage occurs both directly and indirectly through various mediators such as cyclooxygenase, lipoxygenase, cytokines, and oxygen-derived free radicals. ${ }^{25} \mathrm{EtOH}$ and its metabolites (ac- 
Table 1. Effects of Both Extracts (DCM and MeOH) Obtained from A. ananassoides Leaves on HCl/EtOH-, NSAID (Piroxicam)-, and Absolute EtOH-Induced Gastric Ulcers in Rodents

\begin{tabular}{|c|c|c|c|c|c|}
\hline $\begin{array}{l}\text { Gastric lesion } \\
\text { model, extract }\end{array}$ & $\begin{array}{l}\text { Treatment } \\
\text { (per oral) }\end{array}$ & $\begin{array}{c}\text { Dose }(\mathrm{mg} / \mathrm{kg} \text { of } \\
\text { body weight }\end{array}$ & $\begin{array}{l}\text { Number of } \\
\text { animals }\end{array}$ & $\begin{array}{l}U L I \\
(\mathrm{~mm})\end{array}$ & $\begin{array}{l}\text { Inhibition } \\
(\%)\end{array}$ \\
\hline \multicolumn{6}{|c|}{$\mathrm{HCl}-\mathrm{EtOH}$ (mice) } \\
\hline \multirow[t]{5}{*}{ DCM } & Vehicle & - & 8 & $73.40 \pm 7.42$ & - \\
\hline & Lansoprazole & 30 & 7 & $46.00 \pm 9.18 *$ & 37 \\
\hline & Extract & 250 & 8 & $41.00 \pm 7.78^{* *}$ & 44 \\
\hline & & 500 & 7 & $15.81 \pm 3.46^{* *}$ & 79 \\
\hline & & 1,000 & 7 & $20.73 \pm 4.12 * *$ & 72 \\
\hline \multirow[t]{5}{*}{$\mathrm{MeOH}$} & Vehicle & - & 7 & $98.14 \pm 18.81$ & - \\
\hline & Lansoprazole & 30 & 8 & $53.12 \pm 6.38 *$ & 46 \\
\hline & Extract & 250 & 8 & $100.50 \pm 10.90$ & - \\
\hline & & 500 & 8 & $60.34 \pm 6.06$ & 38 \\
\hline & & 1,000 & 8 & $47.00 \pm 11.82^{*}$ & 52 \\
\hline \multicolumn{6}{|c|}{ Piroxicam (mice) } \\
\hline \multirow[t]{5}{*}{$\mathrm{DCM}$} & Vehicle & - & 8 & $18.87 \pm 3.14$ & - \\
\hline & Cimetidine & 100 & 8 & $6.62 \pm 1.15^{* *}$ & 65 \\
\hline & Extract & 250 & 5 & $13.80 \pm 3.32$ & 27 \\
\hline & & 500 & 4 & $15.75 \pm 5.02$ & 17 \\
\hline & & 1,000 & 5 & $8.60 \pm 0.51 *$ & 54 \\
\hline \multirow[t]{5}{*}{$\mathrm{MeOH}$} & Vehicle & - & 8 & $21.87 \pm 1.41$ & - \\
\hline & Cimetidine & 100 & 8 & $6.37 \pm 0.59 * *$ & 71 \\
\hline & Extract & 250 & 5 & $20.80 \pm 1.83$ & - \\
\hline & & 500 & 5 & $14.60 \pm 4.32$ & 33 \\
\hline & & 1,000 & 5 & $7.60 \pm 1.21 *$ & 65 \\
\hline \multicolumn{6}{|c|}{ Absolute EtOH (rats) } \\
\hline \multirow[t]{5}{*}{ DCM } & Vehicle & - & 6 & $76.51 \pm 15.00$ & - \\
\hline & Lansoprazole & 30 & 6 & $61.22 \pm 14.14$ & 20 \\
\hline & Extract & 250 & 5 & $27.41 \pm 10.30 *$ & 64 \\
\hline & & 500 & 5 & $4.80 \pm 1.80 * *$ & 94 \\
\hline & & 1,000 & 5 & $2.40 \pm 0.87 * *$ & 97 \\
\hline \multirow[t]{5}{*}{$\mathrm{MeOH}$} & Vehicle & - & 5 & $125.0 \pm 25.10$ & - \\
\hline & Lansoprazole & 30 & 5 & $69.41 \pm 19.41$ & 45 \\
\hline & Extract & 250 & 5 & $109.61 \pm 15.10$ & 12 \\
\hline & & 500 & 5 & $70.0 \pm 16.72$ & 44 \\
\hline & & 1,000 & 5 & $66.0 \pm 12.50$ & 47 \\
\hline
\end{tabular}

Data are mean \pm SE values.

For the ulcer index in the HCl-EtOH model, ANOVA for DCM, $F_{4,32}=19.6(P<.05)$; for $\mathrm{MeOH}, F_{4,34}=5.06$. For the ulcer index in the piroxicam model, ANOVA for DCM, $F_{4,25}=3.93(P<.05)$; for MeOH, $F_{4,26}=(P<.05)$. For the ulcer index in the absolute EtOH model, ANOVA for DCM, $F_{4,22}=21.7(P<.05)$; for $\mathrm{MeOH}, F_{4,20}=1.9(P>.05)$. Significantly different values from vehicle by Dunnett's test are indicated: $* P<.05$, $* * P<.001$.

etaldehyde) promote tumor development by generating free radical (superoxide, peroxide, and hydroxyl), and $\mathrm{EtOH}$ is directly cytotoxic and facilitates the development of oropharyngeal, esophageal, gastric, and colon cancer. ${ }^{26}$

The best results were obtained using the absolute $\mathrm{EtOH}$ model. One hour before induction of the gastric lesion, oral administration of DCM extract significantly decreased the ULI in a dose-dependent manner (Table 1), with reduction in not only the size but also the severity of the wounds. Promising results were obtained using $500 \mathrm{mg} / \mathrm{kg}$ of the crude extract, which led to $94 \%$ inhibition. In addition, administration of the $\mathrm{MeOH}$ extract did not show any significant activity in this model. The interesting point of this result is that people commonly use the tea form of this medicinal plant against ulcer and gastric pains, which, based on our result, does not represent the best manner to extract anti-ulcer compounds. Accordingly, our study showed that best results were obtained with the DCM extract of $A$. ananassoides.

The velocity of intestinal travel is one of the factors that affected the intensity of luminal absorption, induced peptic ulcer, and probably regulated the bioavailability of the drug when orally administered. ${ }^{27}$ Thus, the gut transit test with activated charcoal was carried out in order to determine the effect of DCM and $\mathrm{MeOH}$ extracts from A. ananassoides on intestinal motility. Our data showed that neither extract was able to change the propulsion of charcoal meal in a dose-dependent manner (Table 2).

Since the most promising results were obtained using the DCM extract, we continued our studies using only a single 
Table 2. EfFects of Both Extracts (MeOH and DCM)

Obtained from $A$. anANassoides on Intestinal Propulsion Induced by Activated Charcoal in Mice

\begin{tabular}{lcc}
\hline $\begin{array}{l}\text { Extract, treatment } \\
\text { (peroral) }\end{array}$ & Dose $(\mathrm{mg} / \mathrm{kg})$ & $\begin{array}{c}\text { Distance moved } \\
\text { by charcoal (arcsine) }\end{array}$ \\
\hline DCM & & \\
Vehicle & - & $75.25 \pm 2.36$ \\
Atropine & 5 & $59.20 \pm 2.33^{*}$ \\
Extract & 250 & $71.99 \pm 3.02$ \\
& 500 & $72.66 \pm 5.98$ \\
MeOH & 1,000 & $74.27 \pm 2.18$ \\
Vehicle & & $69.44 \pm 2.76$ \\
Atropine & - & $42.56 \pm 3.75^{* *}$ \\
Extract & 5 & $70.08 \pm 3.01$ \\
& 250 & $75.77 \pm 5.06$ \\
& 500 & $75.11 \pm 3.57$ \\
\hline
\end{tabular}
sine.

There were five mice per group. Data are mean \pm SE values in arc-

ANOVA for DCM extract, $F_{4,20}=4.03(P<.05)$; for MeOH extract, $F_{4,20}=12.7$. Significant differences by Dunnett's test are indicated: $* P<.05, * * P<.01$.

dose $(500 \mathrm{mg} / \mathrm{kg})$ in the subsequent assays with the purpose of investigating the probable anti-ulcerogenic mechanism involved in the action promoted by this extract.

It is well known that nitric oxide is involved in the modulation of gastric mucosal integrity and is important in the regulation of acid, alkaline, and mucus secretion and gastric mucosal blood flow. ${ }^{28}$ In order to investigate the role of endogenous nitric oxide in cytoprotection, we used the nitric oxide synthetase inhibitor L-NAME to assess the protective effect of the DCM extract on EtOH-induced gastric hemorrhagic lesions (Table 3). Pretreatment with L-NAME did not alter the cytoprotection induced by the DCM extract. Oral administration of the DCM extract $(500 \mathrm{mg} / \mathrm{kg})$ to L-NAME (70 mg/kg, i.p.)-pretreated animals produced a reduction in gastric hemorrhagic lesions when compared to the L-NAMEpretreated control value. The gastroprotective effect of the DCM extract observed after pretreatment with L-NAME $(13.20 \pm 3.34 \mathrm{~mm})$ was similar to that presented by pretreatment with saline $(17.60 \pm 5.47 \mathrm{~mm})$. This result indicates that pretreatment with L-NAME did not alter the DCM extract-induced cytoprotection of EtOH-induced gastric lesions and hence precludes the role of endogenous nitric oxide in mediating the protective effect of the DCM extract from A. ananassoides.

We also evaluated the biochemical changes promoted by the DCM extract in gastric juice parameters of mice subjected to pylorus ligature (Table 4). Intraduodenal administration of the DCM extract significantly decreased the gastric juice production, similarly to cimetidine. However, the DCM extract did not promote any change in $\mathrm{pH}$ or total gastric acid values. Therefore, this result suggests that the DCM extract does not exert an antisecretory effect.

The synthesis of mucus that strengthens the mucosal barrier against harmful agents also has an important function in gastric protection. The continuous adherent mucus layer is also a barrier to luminal pepsin, thereby protecting the underlying mucosa from proteolytic digestion. ${ }^{29}$ The adherent mucus gel structure creates an undisturbed layer to support surface neutralization of acid and acts as a protective physical barrier against luminal pepsin. Mucosal subunits are joined by disulfide bridges that, if reduced, render mucus water-soluble. ${ }^{30}$ Accordingly, the literature reports that en-

Table 3. EfFects of the DCM Extract Obtained from A. ananassoides on Gastric Lesions Induced by EtOH in Rats Pretreated with L-NAME (an Inhibitor of Nitric Oxide Synthase) or NEM (a Blocker of Sulfhydryl Groups)

\begin{tabular}{llccc}
\hline $\begin{array}{l}\text { Pretreatment } \\
\text { (intraperitoneal) }\end{array}$ & $\begin{array}{c}\text { Treatment } \\
\text { (peroral })\end{array}$ & $\begin{array}{c}\text { Dose } \\
(\mathrm{mg} / \mathrm{kg})\end{array}$ & $\begin{array}{c}\text { ULI } \\
(\mathrm{mm})\end{array}$ & $\begin{array}{c}\text { Inhibition } \\
(\%)\end{array}$ \\
\hline $\begin{array}{l}\text { Nitric oxide inhibitor } \\
\text { Saline }\end{array}$ & Vehicle & - & $43.59 \pm 12.70^{\mathrm{a}}$ & - \\
& Carbenoxolone & 100 & $9.0 \pm 4.11^{\mathrm{b}}$ & 79 \\
& DCM & 500 & $17.60 \pm 5.47^{\mathrm{b}}$ & 60 \\
L-NAME & Vehicle & - & $59.19 \pm 11.50^{\mathrm{a}}$ & - \\
& Carbenoxolone & 100 & $15.80 \pm 3.25^{\mathrm{b}}$ & 73 \\
Sulfhydryl blocker & DCM & 500 & $13.20 \pm 3.34^{\mathrm{b}}$ & - \\
Saline & Vehicle & - & $120.0 \pm 22.49^{\mathrm{a}}$ & 88 \\
& Carbenoxolone & 100 & $14.19 \pm 4.14^{\mathrm{b}}$ & 98 \\
NEM & DCM & 500 & $2.60 \pm 0.51^{\mathrm{b}}$ & - \\
& Vehicle & - & $182.80 \pm 10.30^{\mathrm{a}}$ & 57 \\
& Carbenoxolone & 100 & $78.0 \pm 2.57^{\mathrm{b}}$ & 37 \\
\hline
\end{tabular}

Data are mean $\pm \mathrm{SE}$ values. There were five animals per group.

For the EtOH model, ANOVA with Tukey's test $(P<.05)$ was calculated. Different letters represent statistically significant differences. 
Table 4. Effects of the DCM Extract Obtained from A. ananassoides Administered by the Intraduodenal Route on the Biochemical Parameters of Gastric Juice in Pylorus-Ligated Mice

\begin{tabular}{lcccc}
\hline Treatment & $\begin{array}{c}\text { Dose }(\mathrm{mg} / \mathrm{kg}) \text { of } \\
\text { body weight }\end{array}$ & $\begin{array}{c}\text { Number of } \\
\text { animals }\end{array}$ & $p H$ (units) & Gastric juice $(\mathrm{mL})$ \\
\hline Vehicle & - & 11 & $2.0 \pm 0.25$ & $1.28 \pm 0.19$ \\
Cimetidine & 100 & 11 & $3.36 \pm 0.24^{* *}$ & $0.87 \pm 0.08^{*}$ \\
DCM & 500 & 10 & $2.09 \pm 0.09$ & $0.81 \pm 0.08^{*}$ \\
\hline
\end{tabular}

Data are mean $\pm \mathrm{SE}$ values.

ANOVA for $\left[\mathrm{H}^{+}\right], F_{2,29}=3.73$; for $\mathrm{pH}, F_{2,29}=13.52$; for gastric juice, $F_{2,29}=4.18$. Statistically significant differences by Dunnett's test are indicated: $* P<.05, * * P<.001$.

dogenous non-protein sulfhydryls are key compounds in mucosal protection against EtOH-induced gastric injury. ${ }^{31}$ Usually, the growth in damage is accompanied by a decrease in concentration of mucosal non-protein sulfhydryl compounds, because the $\mathrm{SH}$ groups bind the free radicals formed due to the action of noxious agents.

For this reason, we investigated the possible involvement of endogenous non-protein sulfhydryls in the gastroprotective effect of the DCM extract by pretreating animals with NEM, an $\mathrm{SH}$ group blocker, in EtOH-induced gastric lesions (Table 3). Pretreatment of animals with NEM markedly increased the gastric lesions when compared to control groups. Animals treated with DCM extract showed a significant reduction in the ULI (98\% with saline vs. $37 \%$ with NEM). These findings suggest that the increase in endogenous SH groups is in- volved in the protective effects of the DCM extract. Matsuda et al..$^{32}$ suggest that endogenous prostaglandins and sulfhydryl compounds are also involved in the protective effects of phenylpropanoids isolated from rhizomes of Alpinia galanga that were also present in A. ananassoides.

As part of the present pharmacological study, the acute toxicity in mice of the DCM extract obtained from aerial parts of $A$. ananassoides was then investigated. A single oral administration of DCM extract from A. ananassoides did not produce any visible signs or symptoms of toxicity in the treated animals. After 14 days of administration of DCM extract, no animal died, and no significant macroscopic changes in daily body or organ weight were observed. At autopsy, no significant macroscopic change or lesion was observed in the viscera of any animal (data not shown).

Table 5. Mutagenic Activity of MeOH and DCM Extracts from A. ananassoides in $S$. typhimurium Strains in the Presence (+S9) and Absence (-S9) of Metabolic Activation

\begin{tabular}{|c|c|c|c|c|c|c|c|c|}
\hline \multirow{3}{*}{$\begin{array}{l}\text { Treatment } \\
\text { (mg per plate) }\end{array}$} & \multicolumn{8}{|c|}{ Number of revertants per plate in $\mathrm{S}$. typhimurium strain } \\
\hline & \multicolumn{2}{|c|}{ TA98 } & \multicolumn{2}{|c|}{ TA100 } & \multicolumn{2}{|c|}{ TA102 } & \multicolumn{2}{|c|}{ TA97a } \\
\hline & $-S 9$ & $+S 9$ & $-S 9$ & $+S 9$ & $-S 9$ & $+S 9$ & $-S 9$ & $+S 9$ \\
\hline \multicolumn{9}{|l|}{$\mathrm{MeOH}$} \\
\hline 0 & $33 \pm 3$ & $33 \pm 2$ & $104 \pm 6$ & $132 \pm 5$ & $351 \pm 2$ & $379 \pm 14$ & $136 \pm 6$ & $159 \pm 2$ \\
\hline 2.75 & $38 \pm 2(1.2)$ & $30 \pm 2(0.9)$ & $108 \pm 3(1.3)$ & $126 \pm 1(1.0)$ & $305 \pm 7(0.9)$ & $350 \pm 6(0.9)$ & $142 \pm 22(1.1)$ & \\
\hline 5.25 & $41 \pm 3(1.3)$ & $28 \pm 4(0.9)$ & $158 \pm 12(1.6)^{*}$ & $134 \pm 4(1.0)$ & $389 \pm 4(1.1)$ & $390 \pm 15(1.0)$ & $139 \pm 4(1.0)$ & $154 \pm 4(1.0)$ \\
\hline 10.5 & $58 \pm 3(1.8)^{*}$ & $27 \pm 2(0.8)$ & $225 \pm 20(2.2)^{*}$ & $134 \pm 2(1.0)$ & $405 \pm 6(1.2)$ & $364 \pm 12(1.0)$ & $134 \pm 3(1.0)$ & $164 \pm 6(1.0)$ \\
\hline 15.75 & $105 \pm 11(3.2)^{* *}$ & $29 \pm 4(0.9)$ & $298 \pm 16(2.9)^{* *}$ & $143 \pm 10(1.1)$ & $457 \pm 6(1.3)$ & $375 \pm 10(1.0)$ & $155 \pm 19(1.1)$ & $173 \pm 10(1.1)$ \\
\hline 21.0 & $126 \pm 6(3.9)^{* *}$ & $27 \pm 3(0.8)$ & $388 \pm 19(3.7)^{* *}$ & $166 \pm 8(1.3)$ & $485 \pm 3(1.4)$ & $489 \pm 19(1.3)$ & $129 \pm 7(1.0)$ & $181 \pm 7(1.1)$ \\
\hline Positive control & $605 \pm 28$ & $434 \pm 21$ & $1,949 \pm 72$ & $1,438 \pm 124$ & $1,430 \pm 33$ & $877 \pm 108$ & $1,113 \pm 54$ & $2,232 \pm 80$ \\
\hline \multicolumn{9}{|c|}{ DCM } \\
\hline 0.0 & $33 \pm 3$ & $33 \pm 2$ & $104 \pm 6$ & $132 \pm 5$ & $285 \pm 14$ & $379 \pm 14$ & $136 \pm 4$ & $159 \pm 2$ \\
\hline 0.04 & & & & & $407 \pm 10(1.4)$ & $395 \pm 8(1.0)$ & $140 \pm 5(1.0)$ & $190 \pm 5(1.2)$ \\
\hline 0.09 & & & & & $379 \pm 4(1.3)$ & $375 \pm 8(1.0)$ & $147 \pm 9(1.1)$ & $195 \pm 2(1.2)$ \\
\hline 0.17 & & & & & $281 \pm 13(1.0)$ & $418 \pm 4(1.1)$ & $140 \pm 3(1.0)$ & $181 \pm 6(1.1)$ \\
\hline 0.26 & & & & & $214 \pm 8(0.8)$ & $415 \pm 7(1.1)$ & $146 \pm 4(1.1)$ & $203 \pm 9(1.3)$ \\
\hline 0.35 & & & & & $207 \pm 2(0.7)$ & $372 \pm 9(1.0)$ & $119 \pm 3(0.9)$ & $193 \pm 5(1.2)$ \\
\hline 1.75 & $39 \pm 4(1.2)$ & $23 \pm 2(0.7)$ & $118 \pm 0(1.1)$ & $131 \pm 3(1.0)$ & & & & \\
\hline 3.5 & $43 \pm 4(1.3)$ & $24 \pm 1(0.7)$ & $124 \pm 6(1.2)$ & $128 \pm 2(1.0)$ & & & & \\
\hline 7.0 & $45 \pm 4(1.4)$ & $27 \pm 4(0.8)$ & $109 \pm 8(1.0)$ & $142 \pm 3(1.1)$ & & & & \\
\hline 10.5 & $35 \pm 5(1.1)$ & $24 \pm 1(0.7)$ & $116 \pm 15(1.1)$ & $128 \pm 5(1.0)$ & & & & \\
\hline 14.0 & $38 \pm 6(1.2)$ & $25 \pm 3(0.8)$ & $113 \pm 3(1.1)$ & $105 \pm 5(0.8)$ & & & & \\
\hline Positive control & $605 \pm 28$ & $434 \pm 21$ & $1,949 \pm 72$ & $1,438 \pm 124$ & $1,604 \pm 81$ & $877 \pm 108$ & $926 \pm 44$ & $2,232 \pm 80$ \\
\hline
\end{tabular}

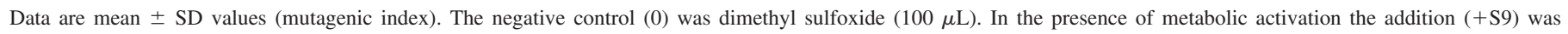

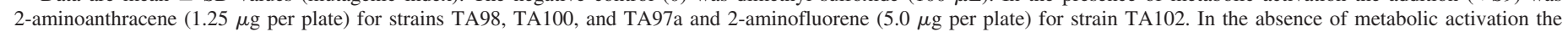

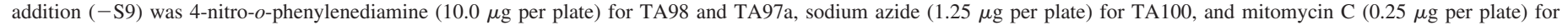
TA102.

Statistically different values by ANOVA are indicated: $* P<.05$, $* * P<.01$. 
The use of ethnomedicinal information has been contributing to health globally through the isolation of bioactive compounds for direct use in medicine. Therefore, it is imperative to evaluate the mutagenic potential of these compounds. ${ }^{33}$ Short-term tests that detect genetic damage have provided information permitting evaluation of the carcinogenic risk of a chemical to humans. ${ }^{34}$ The Ames assay, which is recommended for testing the mutagenicity of chemical compounds with potential pharmacological application, ${ }^{35}$ was used in the present study that was undertaken to assess the mutagenic effect of $A$. ananassoides extracts (Table 5).

When mutagenic activity was evaluated the results obtained showed that the $\mathrm{MeOH}$ extract induced a significant increase in the number of mutant revertants in the TA98 and TA100 strains, in the absence of metabolic activation, suggesting the presence in the extract of direct mutagens that induced frameshift-type mutations and base pair substitution. But when the DCM extract was tested, no mutagenic effect was observed (Table 5). These results are very interesting, since the most promising results in anti-ulcer activity were obtained using the DCM extract. This extract was evaluated by phytochemical analysis, and we detected the presence of hydrocarbons, polyisoprene derivatives, fatty acid esters, steroids (campesterol, stigmasterol, and sitosterol), and phenylpropanoid acids (caffeic acid and its derivatives). The literature reports the chemopreventive action and anti-ulcer effects of caffeic acid and its derivatives, ${ }^{36}$ which probably contributed to the absence of both mutagenic activity and gastroprotective effects of the DCM extract of $A$. ananassoides.

In conclusion, the data obtained demonstrated the gastric anti-ulcer activity of the DCM extract from the aerial parts of $A$. ananassoides. This effect involves an augmented defense mechanism of the gastrointestinal mucosa against aggressive factors, since we observed a strong participation of $\mathrm{SH}$ groups in preventing or attenuating the ulcer process. Our data, taken together with the absence of acute toxicity and mutagenicity of the DCM extract of A. ananassoides, indicate the promising use of this species against gastric disease.

\section{ACKNOWLEDGMENTS}

The authors are grateful to FAPESP for financial support. All pharmacological study was supported by Brazilian grants obtained from $\mathrm{CNPq}$ and FAPESP.

\section{REFERENCES}

1. Wallace J: Mechanisms of protection and healing: current knowledge and future research. Am J Med 2001;110(Suppl):19S-22S.

2. Zayachkivska OS, Konturek SJ, Drozdowicz D, Konturek PC, Brzozowski T, Ghegotsky MR: Gastroprotective effects of flavonoids in plant extracts. J Physiol Pharmacol 2005;56:219-231.

3. Silva SR, Silva AP, Munhoz CB, Silva MC Jr, Medeiros MB: Guia de Plantas do Cerrado Utilizadas na Chapada dos Veadeiros. WWF, Brasília, 2001, p. 97.
4. Silva EM, Hiruma-Lima CA, Lólis SF: Etnobotânica no município de Porto Nacional [abstract]. In: Symposium of Brazilian Medicinal Plants, SBPM, Cuiabá, 2000, p.106.

5. Olfert ED, Cross BM, McWilliam AA: Guide to the Care and Use of Experimental Animals. Canadian Council on Animal Care, Ontario, 1993, p. 213.

6. Mizui T, Doteuchi M: Effect of polyamines on acidified ethanolinduced gastric lesions in rats. Jpn J Pharmacol 1983;33:939-345.

7. Szelenyi I, Thiemer K: Distention ulcer as a model for testing of drugs for ulcerogenic side effects. Arch Toxicol 1978;41:99-105.

8. Puscas I, Puscas C, Coltau M, Pasça R, Torres J, Márquez M, Herrero E, Fillat O, Ortiz JA: Comparative study of the safety and efficacy of ebrotidine versus ranitidine and placebo in the prevention of piroxicam-induced gastroduodenal lesions. Arzneimittelforschung 1997;47:568-572.

9. Morimoto Y, Shimohara K, Oshima S, Sukamoto T: Effects of the new anti-ulcer agent KB-5492 on experimental gastric mucosal lesions and gastric mucosal defensive factors, as compared to those of terprenone and cimetidine. Jpn J Pharmacol 1991;57:595-605.

10. Stickney JC, Northup DW: Effect of gastric emptying upon propulsive motility of small intestine in rat. Proc Soc Exp Biol Med 1959;101:582-583.

11. Arrieta J, Benitez J, Flores E, Castillo C, Navarrete A: Purification of gastroprotective triterpenoids from stem bark of $\mathrm{Am}$ phipterygium adstringens; roles of prostaglandins, sulphydryls, nitric oxide and capsaicin neurons. Planta Med 2003;69:905-909.

12. Shay H, Komarov SA, Fels SS, Meranze D, Gruenstein M, Siplet $\mathrm{H}$ : A simple method for the uniform production of gastric ulceration in the rat. Gastroenterology 1945;5:43-61.

13. Matsuda H, Li Y, Yoshikawa M: Roles of capsaicin-sensitive sensory nerves, endogenous nitric oxide, sulphydryls, and prostaglandins in gastroprotection by mormodin Ic, an oleanolic acid oligoglycoside, on ethanol-induced gastric mucosal lesion in rats. Life Sci 1999;65:27-32.

14. Souza Brito ARM: Manual de Ensaios Toxicológicos In Vivo. Editora da Unicamp, Campinas, Brazil, 1995, p. 15.

15. Maron DM, Ames BN: Revised methods for the Salmonella mutagenicity test. Mutat Res 1983;113:173-225.

16. Bernstein L, Kaldor J, McCann J, Pike MC: An empirical approach to the statistical analysis of mutagenesis data from the Salmonella test. Mutat Res 1982;97:267-281.

17. Varella SD, Pozzeti GL, Vilegas W, Varanda EA: Mutagenic activity in garbage from an aluminum products factory in Salmonella/microsome assay. Toxicol In Vitro 2004;18:895-900.

18. Rates SMK: Plants as source of drugs. Toxicon 2001;29:603-603.

19. Hiruma-Lima CA, Gracioso JS, Bighetti EJ, Grassi-Kassisse DM, Nunes DS, Brito AR: Effect of essential oil obtained from Croton cajucara Benth. on gastric ulcer healing and protective factors of the gastric mucosa. Phytomedicine 2002;9:523-529.

20. Sannomiya M, Fonseca VB, da Silva MA, Rocha LR, Dos Santos LC, Hiruma-Lima CA, Souza Brito AR, Vilegas W: Flavonoids and antiulcerogenic activity from Byrsonima crassa leaves extracts. J Ethnopharmacol 2005;97:1-6.

21. Konturek PC, Brzowski T, Sliwowsk Z, Pajido R, Stachura J, Hahn EG, Konturek SJ: Involvement of nitric oxide and prostaglandins in gastroprotection induced by bacterial lipopolysaccharide. Scand J Gastroenterol 1998;33:691-700.

22. Navarrete A, Trejo-Miranda JL, Reyes-Trejo L: Principles of root bark of Hippocratea excelsa (Hippocrataceae) with gastroprotective activity. J Ethnopharmacol 2002;79:383-388. 
23. Laine L: Approaches to nonsteroidal anti-inflammatory drug use in the high-risk patient. Gastroenterology 2001;120:594-606.

24. Park S, Hahm K, Oh T, Jin J, Choue R: Preventive effect of the flavonoids, wogonin, against ethanol-induced gastric mucosal damage in rats. Dig Dis Sci 2004;49:384-394.

25. Tarnawski A, Stachura J, Hollander D, Sarfeh IJ, Bogdal J: Cellular aspects of alcohol-induced injury and prostaglandin protection of the human gastric mucosa. J Clin Gastroenterol 1988; 10(Suppl):S35-S45.

26. Bujanda L: The effects of alcohol consumption upon the gastrointestinal tract. Am J Gastroenterol 2000;95:3374-3382.

27. Lee HT, Lee YJ, Chung SJ, Shim CK: Effect of prokinetic agents, cisapride and metoclopramide, on the bioavailability in humans and intestinal permeability in rats of ranitidine, and intestinal charcoal transit in rats. Res Commun Mol Pathol Pharmacol 2000; 108:311-323.

28. Chandranath SI, Bastaki SM, Singh J: A comparative study on the activity of lansoprazole, omeprazole and PD-136450 on acidified ethanol- and indomethacin-induced gastric lesions in the rat. Clin Exp Pharmacol Physiol 2002;29:173-180.

29. Allen A, Flemstrom G: Gastroduodenal mucus bicarbonate barrier: protection against acid and pepsin. Am J Cell Physiol 2005; 288:C1-C19.
30. Avila JR, De la Lastra CA, Martin MJ, Motilva V, Luque I, Delgado D, Esteban J, Herrerias J: Role of endogenous sulphydryls and neutrophil infiltration in the pathogenesis of gastric mucosal injury induced by piroxicam in rats. Inflamm Res 1996;45:83-88.

31. Szabo S, Vattay P: Experimental gastric and duodenal ulcers. $\underline{A d v}$ Pathogenesis Gastroenterol Clin North Am 1990;19:67-85.

32. Matsuda H, Pongpiriyadacha Y, Morikawa T, Ochi M, Yoshikawa M: Gastroprotective effects of phenylpropanoids from the rhizomes of Alpinia galanga in rats: structural requirements and mode of action. Eur J Pharmacol 2003;471:59-67.

33. Fabricant TS, Farnsworth NR: The value of plants used in traditional medicine for drug discovery. Environ Health Perspect 2001;109:69-75.

34. Zeiger E: Identification of rodent carcinogens and non-carcinogens using genetic toxicity tests: premises, promises, and performance. Regul Toxicol Pharmacol 1998;28:85-95.

35. Mortelmans K, Zeiger E: The Ames Salmonella/microsome mutagenicity assay. Mutat Res 2000;455:29-60.

36. Carrasco-Legleu CE, Marques-Rosado L, Fatel-Fazenda S, ArcePopoca E, Perez-Carreon JI, Villa-Trevino S: Chemoprotective effect of caffeic acid phenethyl ester on promotion in a mediumterm rat hepatocarcinogenesis assay. Int J Cancer 2004;108: 488-492. 
This article has been cited by:

1. Roberta Gomes Coelho, Neli Kika Honda, Maria do Carmo Vieira, Rosenei Louzada Brum, Fernando Rogério Pavan, Clarice Queico Fujimura Leite, Claudia Andréa Lima Cardoso. 2010. Chemical Composition and Antioxidant and Antimycobacterial Activities of Bromelia balansae (Bromeliaceae). Journal of Medicinal Food 13:5, 1277-1280. [Abstract] [Full Text HTML] [Full Text PDF] [Full Text PDF with Links] 